\title{
Construct Satisfaction Scale for Counseling Scientific Colleges Students in Al Hashimia University
}

\author{
Mohammad Olaimat \\ Jordan-Al-Albayt University, Jordan
}

\begin{abstract}
The purpose of this study is to construct satisfaction scale counseling among scientific students in Al-Hashimia University. The scale consist of 28 items has been validated and verified .sample of 320 students .responses analyzed in SPSS package using ( $T$ test, ANOVA, Median and standard deviations). The result showed that is a satisfaction counseling among scientific students, the study recommended using this scale in evaluate problems faced students and emphasize in training counselors to be profession in their job.
\end{abstract}

\section{Introduction}

Counseling has become much needed because it helps the individuals attain psychological a social growth and maturity which leads to progress and welfare. [28]

In university life students sometimes find themselves threatened by crisis situation, bad feeling. It needs from student's responsibility, manage his/her time, participation in activities, limit priorities, moral decision, and arrange hours between classes and how to face Graduation requirements which differ from year to year. Student responsible for what he does and does not do, as well as for the consequences of his/her decision. Our goal to help students achieve as much success as possible

Since the main goal of counseling is to help the individual achieve both personal social harmonies, the psychological counseling has become a basic need for individual like security, love, achievement, and social belongingness [34]. If this individual is satisfied and happy, he will be optimist and psychologically- integrated. But if he feels that his goals and ambitions have been aborted, he will be desperate and dissatisfied [20] [10].

As a result, psychological counseling has become a basic need for students to help them adapt psychologically and socially to live peacefully [27].

Since the university students lead different changeable life with several psychological problems, so it is necessary to construct a satisfaction scale about counseling among the students of the universities of Jordan.

\section{Literature review}

\subsection{Study problem}

Researchers have dealt with the qualities which characterize individual personality such mental abilities which characterize individual personality such mental abilities, communication skills, maturity, responsibility, social skill. All of these items play an important role in individual adaptability with changeable situations which make the individual either satisfied or frustrated [18].

Since measurement is considered the scientific tool in accurate objective description for psychological aspects and it gives exact description based on mathematical and statistical operations [2].

The specialist in psychological measurement fact great difficulties to reach correct measurement for psychological features compared to natural phenomena because it is indirect measures phenomenon through its behavior so it doesn't reach the relative measurement (ration), but its limit is the interval level [17].

It is impossible to measure the actual degree of the trait or psychological characteristic without mistakes which may increase or decrease according to the accuracy of the resources especially the accuracy of psychological measurement [17]. the accuracy of the results depends, to a large extent, on the accuracy of measurement used for target trait. [6]. the importance of psychological measurement shows that is a basic element in psychological studies because all studies include this item [12]. Consequently, it is necessary to have accurate measures and tools characterized by good psychological traits by preparing suitable items showing this trait [37]. Thereupon, the measure is a group of stimulants prepared in an objective way to suit the behavior me intend to measure [1]. In addition to the importance of measurement which represents the first part of this research, the satisfied personality is the second part. The objective measures are necessary measure the students satisfaction about psychological guidance in Jordan which is considered an important academic achievement theoretically and practically because the construction of any measure requires us to refer to its literature and related studies to determine the students personality. We can select the suitable 
method and formulate verbal items which reflect the select method and formulate the items to be experimented to find the psychometric characteristics which lead to the final formula of the measure.

\subsection{Study Terms}

- Counseling:

It aims to help the student learn to understand himself such as his aptitudes, abilities, tendencies, and to know his motivations and ways of life to evaluate [7].

- Guidance process:

It uses scientific and practical methods to evoke the individual's potentials to produce a prosperous society [13].

- Measurement:

It is the quality a trait exists in the individuals or things which can be transformed to symbols and figures controlled by certain rules [16].

- Self- satisfaction:

It is defined by pain as "a psychological feeling which may have positive a negative effect depending on the individuals psyche and related to the individual's feeling. The psychological satisfaction about the guidance makes [19].

- Scientific colleges:

Teaching scientific subjects which need scientific abilities.

\section{Research Rationale}

Guidance is necessary to help the individual to grow and become nature psychologically and socially to achieve development and welfare. So the positive attitudes to participate in the societal activities to achieve the individual's psychological maturity and his sense of responsibility and belonging to his society where he lives [28]. These services are considered basic needs for universities to achieve psychological and social adaptation, and to move peacefully to the life [27].

Since each individual has his own way and behavior, and his traits are different but similar in certain aspects depending on sex, age, environment. This means that there is a bad need for providing all individuals means these services [4]. It is important to measure satisfaction degree among university students about psychological guidance. It is necessary to build up guidance centers, counselors, and to keep environment suitable for guidance using various tools and means so it is also necessary to construct measures in the university environment, to measure satisfaction about guidance among their students to know the role of guidance in the universities as viewed by their students.

\section{Questions of study}

In this research we outlined the following questions:

1 - Is their satisfaction about guidance among the university students?

2 - Are there any differences with statistical significance about the satisfaction about guidance among the university students according to the sex variable?

3 - Are there any differences with statistical significance about the satisfaction about guidance among university students according to level variables?

\section{Previous studies}

The individual with high degree adaptability and personal traits can express his abilities and potentials well so he will deal properly with his life situations [14]. the psychological counselor is a dynamic and creative person whose success depends greatly on his personality, flexibility, and how he deals with students [15].

In another study conducted by Paterson 1982, he showed that the latest method of guidance is based on the hypothesis that students are unable to recognize their abilities and tendencies so that they need an expert to help them moreover, we should know the complicated factors included in the process of selection of students, and any chance in behavior leads to a change in thoughts and feelings which makes both counselor and the process of guidance to do further research [8].

Another study by Al-Kateeb about personal factor related to the efficacy of psychological guidance, showed that there are five factors related to the efficiency of the counselor according to kettle test for effective counselor [9] study 1991 about the factors that affect the counselor personality which revealed six traits that have statistical influence at level 0, 05 such as: relaxed conscientious, imaginative, innovative, independent and disciplined.

In Franc, "Loing" carried out a study in 1976 about the borders between the duties of psychologist and vocational counselor. He found not that counselors work in educational institutions at three ways with the staff. They work as psychologists to help students adapt and know the difficulties which lead to failure, as specialists in giving students information about job opportunities, requirements, and field of study tiling into consideration the educational needs of the young, and finally they put the strategies to accomplish personal future plans for the students [24].

Marlowe, who carried out another experimental study to the relative tale of the counselor in reducing the undesirable conduct among students, found out that he can reduce this behavior to $40 \%$ among the troubled students [25]. 
In the study carried by Alabed and Fateem in Gulf countries 1984, the challenges which face guidance had been studied in (Bahrain, KSA, Iraq, Oman, Emirates, Qatar, and Kuwait) such as:

1- The challenge of some psychologists who don't realize the importance of guidance.

2- The challenge of the society which doesn't recognize the counselor and his position or even guidance itself.

3- The challenge of some ministries of education which don't recognize the role guidance in education. [5].

Another study carried out by Abu Al-Heija, 1988 a bent the assessment of counselor's effectiveness in the educational institutions in Jordan. He found out that counselors haven't reached their required educational level, and there is shortage in the effectiveness of counselors in educational institutions [3].

In his study Bake discovered that students who asked for counseling achieved more success than those who did not ask for any help [32].

Wiggins [35] in his study stated self concealment was associated with less favorable attitudes toward seeking help; it was also associated with greater intentions to seek counseling

Darcy [31] in his turn found finally attitudes and believes, knowledge and skills necessary to provide competent psychosociocultural services to Latino students.

Worthington constructed validation of a brief scale for research and counseling different religious [38]. Result scores had strong estimated internal consistency, construct validity, discriminant validity.

In a study discussed self efficacy interests goals, outcome exceptions, social cognitive found the basic construct and their common variation are defined and distinguished unique measurement, concerns are considered and examples and suggestion are offered for measurement design and adaptation [30].

In another study carried by Darcy results said that counseling profession had higher levels of cognitive complexity with highest degree obtained in the counseling profession [31].

The role of the counselor is quite obvious university because students' adaptation is a vital process to continue their study and achieve their desired goals so that it is important to have a tool to measure the satisfaction about guidance among students at universities.

\section{Method and procedures}

Study society: it consists of all students at the second semester 2002- 2003 at Hashimia University.

Study sample: It consists of 420 students both male and female were randomly selected from scientific college in AL Hashimia University.
Third: preparation of initial (primary) formula for measurement with reference to the previous studies and related literature, we constructed 28 items. The initial list was checked by specialists who classified it into three fields: guidance, counselor, and environment. The researcher decided to divide these fields equally as much as possible.

Fourth: construction of measure items:

The following considerations depended in constructing measure (scale):

1- He depended on the Theory of Trait and Factor in constructing satisfaction among university students. This theory aims to help individual for success full choice and to achieve his selfunderstanding by using his abilities and potentials to fact life needs. [19].

2- He also depended on rational and experience method to construct the measure (scale) because some specialists indicated that it is possible to depend on more one method in constructing personality scales, so both trait and factor theory and this method have been used as well as the experience of some specialists in these fields [23].

3- He depended on verbal situation method which starts from personality concept as viewed by the individual himself and his emotional experience enables him to express his needs and ideas honestly, which makes his conduct reflect or represent the internal traits of his personality to a large extent [36].

B- Items formulation: in the light of the abovementioned spring boards and considerations, the definition of the research about pointed in the study, and the researches knowledge about some personality measures, he constructed 28 items of verbal situations. Each item has two answers yes/no; one about trait, the other is different. These items show the situations the university students may face during the daily life at campus.

C- Verification (validity) of items: to verify the validity of each Item in measuring satisfaction about guidance among university students, these items had been checked by some specialists to decide the validity of each item, and if it needs to may modification. Some items were modified and $90 \%$ was the majority decision.

D- Measure instructions preparation: the way of preparation shows how it should be answered. It was pointed that the items of measure don't include yes/no but it require that the individual must show if all alternatives are suitable or not and the respondents were asked not to write their names and they were made sure that their answers were secret and they will only be used for research. Willy emphasized as shown by Allen 1986, that overcoming the factor of social approval could be done by ensuring the respondents that their responses will be secret [11]. before applying the measure in exploratory experiment, three items were repeated to 
make sure of the respondent's seriousness, so the measure will have 3 items at the end.

Fifth: preparing the final formula:

1- Exploratory experiment: the measure has been applied at its initial formula which consists of 31 items (including the three repeated ones) at a sample of 30 students of scientific collage in AL AlBayt University at 2nd and 3rd year. It was revealed that this measure is suitable and stimulates students' interest to answer it.

2- Statistical analysis: the aim of this experiment is to recognize each item of the measure of satisfaction about guidance among university students through statistical analysis to reveal its psychometric characteristics.

A- Sample testing: Some specialists have suggested a number of 5 students in each item [34], others suggest a total of 400 persons as a sample selected according to accurate standards [27] see Table 3.

Table 1. Sample distribution according to sex

\begin{tabular}{|c|c|c|}
\hline Sex & Number & Percentage \\
\hline Male & 157 & $37.4 \%$ \\
\hline Female & 263 & $62.6 \%$ \\
\hline Total & $\mathbf{4 2 0}$ & $\mathbf{1 0 0} \%$ \\
\hline
\end{tabular}

This measure was applied to all sample members by distributing it to all classes during lecture hours, then, the paper were checked to make sure that all items had been answered.

B- Correcting the measure: since each item includes two alternatives, the first represents the positive side of the trait, and the other represents the negative side. We gave (Zero, one) for those alternates successively so the highest grade will be 28 while the lowest will be zero.

C- Statistical analysis of item: this process is considered a basic step to construct a measure. Although it probably reduces these items, it makes the measure more valid and consistent with the other items [1].

Through this process, we can choose the items with good psychometric characteristics and put aside the unsuitable ones [21]. The psychometric characteristics are very significant to recognize of the scale is suitable to measure the things we want as well as its own characteristics [29]. The total degree of the scale has been used as an internal yard stick in this analysis, which leads to pure and homogenous one [21]

1- Item recognition: it is a very important one which is based and to evaluate the efficiency of the item to measure the trait wanted because it reflects its ability to differentiate between individuals who are different in the measured trait [27]. Therefore, we choose the strong items not the week ones to have consistent and accurate scale [22]. In order to measure the strength of items of satisfaction about guidance, answers were down arranged according to total grade, then we chose the highest $27 \%$ as a high group and the lowest $27 \%$ as a lowest group so able thinks that depending on $27 \%$ as highest and lowest makes the two groups the best in terms of size and recognition [22]. the number of papers was 113 in each group, and each item represented interrupted measure (1, zero) and the recognition co-efficient ranged from 057- 22.

Table 2. Items recognition according to correlation factor between each item and total degree

\begin{tabular}{|c|c|}
\hline Item & Correlation factor \\
\hline 1 & $.50 x x$ \\
\hline 2 & .,41xx \\
\hline 3 &., $50 x x$ \\
\hline 4 & . $45 x x$ \\
\hline 5 & .,46xx \\
\hline 6 & .,16xx \\
\hline 7 & , 47xx \\
\hline 8 & $.52 x x$ \\
\hline 9 & , $46 x x$ \\
\hline 10 & . $57 x x$ \\
\hline 11 & $.54 x x$ \\
\hline 12 &., $54 x x$ \\
\hline 13 & $.52 x x$ \\
\hline 14 &., $55 x x$ \\
\hline 15 & $.51 x x$ \\
\hline 16 & $.27 \mathrm{xx}$ \\
\hline 17 & .,38xx \\
\hline 18 & .22xx \\
\hline 19 & .,43xx \\
\hline 20 & .,25xx \\
\hline 21 & . $43 x x$ \\
\hline 22 & .,46xx \\
\hline 23 & .,47xx \\
\hline 24 &., $51 x x$ \\
\hline 25 & .,26xx \\
\hline 26 & .,42xx \\
\hline 27 & $.4 x x$ \\
\hline
\end{tabular}




\begin{tabular}{|l|l|}
\hline 28 &., $43 x x$ \\
\hline
\end{tabular}

B- Item validity: the researcher the dual (binany) correlation co-efficient to find out validity between the degree of each item as interrupted scale and the total degree as a continuous scale. Researchers in psychological guidance indicate that the high relation between the item and total degree means that this item measures the trait the scale measures itself. When we put aside the weak degree and keep the high ones we have a more homogenous and valid scale [1]. the internal homogeneity among the items means that each item can measure the same functions which all items measure. Thereupon, putting the weak ones aside makes the scale more valid. [29]. To achieve this, each correlation co-efficient of each item was calculated in statistical analysis data (420) individuals these co-efficient ranged from 57 to 22 and they have statistical significant at .01 level so the final scale includes 28 items represent the level of satisfaction about psychological guidance.

\section{Discussion}

To answer the questions of the study an application of 28 - item scale was performed by the researcher.

Question 1: Is there satisfaction about guidance among scientific college0 Students? The researcher calculated the means and standard deviations for each field of guidance table [3] shows that counselor's field has the highest mean (14.39) but his environment (12.82) and the guidance field was the lowest (12.14).

Table 3. Means and standard directions for each area and whole measure

\begin{tabular}{|c|c|c|c|}
\hline & Items & Means & $\begin{array}{c}\text { Standard } \\
\text { Deviations }\end{array}$ \\
\hline Guidance & 9 & 12.14 & 2.14 \\
\hline Counselor & 9 & 14.39 & 2.50 \\
\hline Environment & 10 & 12.82 & 2.35 \\
\hline Total & $\mathbf{2 8}$ & $\mathbf{3 9 . 3 4}$ & $\mathbf{5 . 6 2}$ \\
\hline
\end{tabular}

Table 3 shows that the counselor field has the highest value then environment, and the lowest was the guidance which shows that there is a general sense of satisfaction about guidance and this guidance still faces many challenges because a lot of people don't know enough about it. Besides, there is a challenge from society which does not admit the importance or status of counselor. Moreover, there is another challenge from educational institutions which also don't recognize the essential role of guidance in the educational process. Also rover,
Question 2: Is satisfaction among scientific students affected by sex? The means and standard deviations calculated for each field as shown in table [4] which shows statistically significant differences at level (.05) about the range of satisfaction about guidance in its environment due to sex variable which was for male's benefit with (13.3) but female (12.52). Beside, the table shows that there are no statistically significant differences in guidance field, counselor, and the total range due to sex variable

Table 4. (T) Test to examine differences significance at all levels of counseling based on sex variable

\begin{tabular}{|c|c|c|c|c|c|c|}
\hline $\begin{array}{c}\text { Domain } \\
\text { area }\end{array}$ & Sex & Item & Mean & $\begin{array}{c}\text { Standard } \\
\text { Deviations }\end{array}$ & $\begin{array}{c}\text { Freedom } \\
\text { degree }\end{array}$ & $\begin{array}{c}\text { Significance } \\
\text { level }\end{array}$ \\
\hline \multirow{2}{*}{ Guidance } & Male & 157 & 12.19 & 2.19 & 1.636 &., 202 \\
\cline { 2 - 7 } & Female & 263 & 12.1 & 2.11 & & \\
\hline \multirow{2}{*}{ Counselor } & Male & 157 & 14.36 & 2.37 & 1.659 &., 198 \\
\cline { 2 - 7 } & Female & 263 & 14.39 & 2.58 & & \\
\hline \multirow{2}{*}{ Tnvironment } & Male & 157 & 13.3 & 2.65 & 12.633 &.,$*^{*}$ \\
\cline { 2 - 7 } & Female & 263 & 12.52 & 2.1 & &., 28 \\
\hline \multirow{2}{*}{ Total } & Male & 157 & 39.85 & 5.81 & 1.165 &., 28 \\
\cline { 2 - 7 } & Female & 263 & 39.03 & 5.5 & & \\
\hline
\end{tabular}

Table 4 shows that there are statistically significant differences attributed to sex variable and for the benefit of males who have 13.3 as a mean whereas females have 12.5. As a result, it was showed that there were no differences with statistical significance in the field of satisfaction about guidance concerning guidance counselor, and the entire field which shows that sex has no significance a effect on satisfaction about guidance but its environment was effected by sex variable which can be attributed to social bringing up area ring as well as family background.

Question 3: Is satisfaction among scientific students affected by their academic level? The means and standard deviations were calculated for each field separately then totally as shown in table [5]. To know the significance of difference in the range of satisfaction about guidance at every level and for the scale as a whole according to the academic level variable.

Table 5. Differences in means and Standard deviation at all levels based on academic level

\begin{tabular}{|c|c|c|c|c|}
\hline Area & $\begin{array}{c}\text { Level of } \\
\text { study }\end{array}$ & Number & Mean & $\begin{array}{c}\text { Standard } \\
\text { deviation }\end{array}$ \\
\hline
\end{tabular}




\begin{tabular}{|c|c|c|c|c|}
\hline \multirow{6}{*}{ Guidance } & 1 & 124 & 12.6129 & 2.1891 \\
\hline & 2 & 120 & 11.9167 & 2.2439 \\
\hline & 3 & 138 & 12,0000 & 2.0540 \\
\hline & 4 & 35 & 11.8286 & 1.7903 \\
\hline & Master & 3 & 11.0000 & 1.7321 \\
\hline & total & 420 & 12.1357 & 2.1436 \\
\hline \multirow{6}{*}{ Counselor } & 1 & 124 & 14.7097 & 2.5970 \\
\hline & 2 & 120 & 14.2167 & 2.4191 \\
\hline & 3 & 138 & 14.2319 & 2.4946 \\
\hline & 4 & 35 & 14.4286 & 2.6154 \\
\hline & Master & 3 & 14.3333 & 1.1547 \\
\hline & total & 420 & 143857 & 2.5070 \\
\hline \multirow{6}{*}{ Environment } & 1 & 124 & 13.0645 & 2.3487 \\
\hline & 2 & 120 & 12.7167 & 2.3699 \\
\hline & 3 & 138 & 12.7101 & 2.3497 \\
\hline & 4 & 35 & 12.6286 & 2.0592 \\
\hline & Master & 3 & 14.0000 & 1.0000 \\
\hline & total & 420 & 12.8190 & 2.3522 \\
\hline \multirow{6}{*}{ Total } & 1 & 124 & 40.3871 & 5.8611 \\
\hline & 2 & 120 & 38.8500 & 5.6712 \\
\hline & 3 & 138 & 38.9420 & 5.5234 \\
\hline & 4 & 35 & 38.8857 & 4.8976 \\
\hline & Master & 3 & 39.3363 & 2.2146 \\
\hline & total & 420 & 39.3405 & 5.6260 \\
\hline
\end{tabular}

We use the analysis of (ANOVA) and table [6] shows the results of the analysis. If we work at the above table, we see that guidance is affected by the academic level because significance level is 0.040 (a) whereas in other fields such as the counselor and the environment are not affected by the academic level but guidance is affected so it is an evidence the students in different levels have different attitudes towards in different levels have different attitudes toward guidance process and its importance which increases at high academic levels.

Table 6. ANOVA to know the differences at all levels based on academic level

\begin{tabular}{|c|c|c|c|c|c|c|}
\hline Area & Source & \begin{tabular}{|c|} 
Nova \\
squares
\end{tabular} & \begin{tabular}{|c|}
$\begin{array}{c}\text { Free- } \\
\text { dom } \\
\text { degree }\end{array}$ \\
\end{tabular} & \begin{tabular}{|l|} 
Square \\
means
\end{tabular} & $\mathbf{F}$ & $\begin{array}{c}\text { Signi- } \\
\text { ficance } \\
\text { level }\end{array}$ \\
\hline \multirow[t]{3}{*}{ Guidance } & $\begin{array}{c}\text { Among } \\
\text { groups } \\
\text { (error) }\end{array}$ & 43.7 & 4 & 10.93 & 2.410 & , 040 \\
\hline & $\begin{array}{c}\text { Inter } \\
\text { groups }\end{array}$ & 1881.55 & 415 & 4.53 & & \\
\hline & Total & 1925.26 & 419 & & & \\
\hline \multirow[t]{3}{*}{ Counselor } & $\begin{array}{l}\text { Among } \\
\text { groups } \\
\text { (error) }\end{array}$ & 19.78 & 4 & 4.95 & 0.785 & 0.53 \\
\hline & $\begin{array}{c}\text { Inter } \\
\text { groups }\end{array}$ & 2613 & 415 & 6.30 & & \\
\hline & Total & 2633 & 419 & & & \\
\hline \multirow{3}{*}{$\begin{array}{c}\text { Environ- } \\
\text { ment }\end{array}$} & $\begin{array}{c}\text { Among } \\
\text { groups } \\
\text { (error) }\end{array}$ & 15.82 & 4 & 3.96 & 0.713 & 0.58 \\
\hline & $\begin{array}{l}\text { Inter } \\
\text { groups }\end{array}$ & 33.2 & 415 & 5.55 & & \\
\hline & Total & 2318 & 419 & & & \\
\hline \multirow{3}{*}{ Total } & $\begin{array}{c}\text { Among } \\
\text { groups } \\
\text { (error) }\end{array}$ & 193.84 & 4 & & 1.53 & 0.19 \\
\hline & $\begin{array}{l}\text { Inter } \\
\text { groups }\end{array}$ & 12068 & 415 & & & \\
\hline & Total & 13262 & 419 & & & \\
\hline
\end{tabular}

Table 6 shows that guidance is affected by the academic level unlike the fields of satisfaction about guidance such as the counselor and environment which emphasizes that students at various levels have efficient attitudes and vision toward the process of guidance and its importance so the higher the academic level is the more important guidance is in the university life on campus.

\section{Conclusion}

The importance of measurement counseling among scientific students in the university to solve problems faced scientific students, and adaptation safely, until this goal is achieved we recommended: 
- to open guidance centers in colleges and qualified counselors to carry out follow up studies about progress counseling.

- to use this scale by center counseling in the university

- to survey difficult faced students in various colleges.

- to reach a knowledge if there is any difference between students in scientific colleges and human colleges.

\section{References}

[1] A. Anastasi, A., 1988, Psychological testing, New York, Macmillan.

[2] Abdel Khaleq, Ahmad Mohammed, 1983, Personality intelligence, $2^{\text {nd }}$ edition, Alexandors, Dar Alma-rafa, Aljameyeh.

[3] Abu Al-Heiga, Ahamd, 1988, "Assessment of the effectiveness of counselor as Viewed by manager, teachers, and counselors at Jordan School" unpublished Master Thesis, Al-Yarmouk University.

[4] Al-abed, Hamed, Fateem Lateef, 1984, "Challenges which faced guidance in Arab Gulf", a field study, psychological guidance seminal, college of education, Kuwait University.

[5] Al-Chareeb, Ramzyeh, 1985, "Psychological and educational assessment and measurement" Cairo, Egyption, Anglo Library.

[6] Al-Faqi

[7] Al-Hayate, Assem Moh'd, 1989, Educational and psychological guidance "Counseling" Al Mousel University.

[8] Al Khateeb, 1994, Journal of "Human Behavior Modification" Amman, Jordan.

[9] Al Khteeb, Muna Al-Hadeedy, 1996, Journal of "Behavior Modification", Jerusalem Open University publications, Amman.

[10] Allam, Saladin Mahmud, 1988, Modern Developments in Educational and psychological measurement, Kuwait, Alqabas commercial press.

[11] Al-Nahar, Tayseer, 1992, "psychometric qualities of three scales at graduation dimension, Al-Yarmouk Research Periodical, Irbid, Volume 8, $2^{\text {nd }}$ Issue.

[12] Al-Sayed, Mohnd Twfeeq, 1976, "Researches in psychology, Angle Libarary, Egypt.

[13] Al Shamsi, Abdelameer Aboud, 1990, Personality Traits of lectures at university and their relationship to their leadership conduct, unpublished Ph.D thesis, Baghadad University, Ibn Rushd College of Education.
[14] Al-Sheimi Moh'd Ayoub, 1997, "Social Educational and psychological counseling among children, first Edtion, Dar Al feker, Lebanon.

[15] Al-Sukkar, Naheda, 2003, Educational and Psychological Tests and Scales, first imprint, Dar Almanahey, Amman.

[16] Audeh, Ahmad Suleiman, 1998, Measurement and evaluation in the educational process, $2^{\text {nd }}$ edition, Irbid, Dar Alamal.

[17] Al-Taleb, Hisham, 1996, "Leadership Training Directory" Human Development Seires, International Institute of Islamic Thought.

[18] Al Zboun, Salim, 1996, Educational Counsellor his Responsibilities and Duties. Amman.

[19] B. Berger, K., Stassen, 1988, The developing person through child hood and ado lescence (second ed) wroth publishers, Inc. New York, U.S.A.

[20] C. Chiselli, E. E., et al (1981) Measurement theory for the behavioral science, sanfancis freeman L.R.

[21] D. Ebel, R. L., 1972, Essentials of Educational measurement $2^{\text {nd }}$ ed, NewYork: Prentice Hall.

[22] Eleimat, Moh'd Muneizel, 2001, Construction of leadership personality traits of working managers in Jordan. PhD Thesis (unpublished) Baghdad University, Ibn Rushd College of Education.

[23] E. Liong, J., 1976, Information and guidance services in France vocational guidance quartly, Jun, vol 24, No.4.

[24] F. Lord. F.M.., (1960) psychological scaling, New York, John Willy \& Sons.

[25] Marlowe, G., et al., 1978, Sever class room behavior problems teachers or counselors, Journal of Applied Behavior Analysis, No.1.

[26] Hamdi, Nazeeh, Saber Abu Taleb, 1998, "Guidance and Direction at all ages", Jerusalem open university, Amman.

[27] Abdelsattar, I., 1985, "Man and Psychology", Alan Alma'rofeh, Kuwait.

[28] I. Smieh, M., 1966, The relation between item validity and test validity psycho mertricka, vol. 1, No.3, pp. 69- 76.

[29] Jornal of carrer assessment, 2006, vol 14 N. (1) 1235.

[30] Jornal of counseling a Development, 2000, vol. $78 \mathrm{~N}$ (2) spring, p. 145-154.

[31] Darcy, H., G., 2010, Journal of counseling a Development,issue,vol 88 ,winter ,pp: 92-100. 
[32] Bake, R., S., 1984, Journal of counseling psychology, vol. 31 N. (2), pp. 179-1

[33] J. Tan, Hassan, 1967, Intercultural study of counselting expectancies, Journal of consoling psychology, No14, p: 122-130.

[34] Kelly, Anita El Achter, 1995, John A Journal of counseling psychology. Vol. 42 w (1) Jan., 40-46.

[35] K. Wiggins, J. S., 1972, "Personality and prediction" Principles of personality, California, Menlo Park, Addison Wesly.

[36] Sawalmeh Yousef, 1994, The affect of selection matter on internal homogeneity and the level of difficutly of its items, Al-Yarmouk Research Magazine, Irbid, $10^{\text {th }}$ volume, Issue 2.

[37] Worthington G.R., et al., 2003, Journal of counseling psychology, Vol. 50 w (1), Jan. 2003, p 84-96. 